\title{
A Brief Overview of Adolescent Developmental Problems in Hong Kong
}

\author{
Daniel T. L. Shek, ${ }^{1,2,3,4}$ Hing Keung Ma, ${ }^{5}$ and Rachel C. F. Sun ${ }^{6}$ \\ ${ }^{1}$ Department of Applied Social Sciences, The Hong Kong Polytechnic University, \\ Hong Kong \\ ${ }^{2}$ Public Policy Research Institute, The Hong Kong Polytechnic University, Hong Kong \\ ${ }^{3}$ Kiang Wu Nursing College of Macau, Macau \\ ${ }^{4}$ Division of Adolescent Medicine, Department of Pediatrics, University of Kentucky \\ College of Medicine, Lexington, KY 40506, USA \\ ${ }^{5}$ Department of Education Studies, Hong Kong Baptist University, Hong Kong \\ ${ }^{6}$ Faculty of Education, The University of Hong Kong, Hong Kong
}

Received 30 September 2010; Revised 9 February 2011; Accepted 15 August 2011

Academic Editor: Joav Merrick

Several adolescent developmental problems in Hong Kong are briefly reviewed in this paper. First, rising adolescent substance abuse trends are described. Second, Internet use problems and Internet addiction among young people are examined. Third, worrying trends in adolescent sexuality are identified. Fourth, phenomena on bullying among young people are reviewed. Finally, phenomena related to adolescent materialistic orientation are focused upon. With reference to these adolescent developmental problems, possible solutions are briefly discussed particularly with reference to the ecological perspective. It is argued that the related scientific literature provides useful pointers for designing the curriculum in the extension phase of the Project P.A.T.H.S. in Hong Kong.

KEYWORDS: Chinese adolescents, developmental problems, positive youth development, prevention 


\section{INTRODUCTION}

On 18 December 2009, the United Nations General Assembly passed a resolution (A/RES/64/134) to designate the year commencing on 12 August 2010 as the International Year of Youth. As commented by the United Nations Secretary-General Ban Ki-moon, "youth should be given a chance to take an active part in the decision-making of local, national and global levels" (http://social.un.org/youthyear). Adopting a systems' approach, the framework underlying the initiative has several objectives, including creation of awareness (increased recognition that investment in youth is a smart investment, recognition of youth's contribution, increased awareness of inequalities, promotion of evidence-based and research-driven initiatives), mobile youth participation (strengthening mechanisms for youth participation in decisionmaking and strengthening networks and partnership), and connecting and building bridges. One unique feature of this framework is that it emphasizes the important role of research particularly with reference to our understanding of adolescent developmental problems and development of evidence-based youth services and policies in different places, including Hong Kong.

Obviously, one good starting point to nurture young people is to understand what developmental problems they face via systematic research. With specific reference to Hong Kong, Shek [1] examined several adolescent developmental problems in Hong Kong and arrived at several conclusions. First, adolescent substance abuse patterns were changing in Hong Kong. Second, although the overall youth crime trend was relatively stable in the past decade, shoplifting and stealing crimes deserve our concern. Third, adolescent mental health problem was a growing problem. Fourth, unhealthy lifestyles, such as smoking, underage sex and moral confusion, were issues of concern. Fifth, adolescents experiencing economic disadvantage was a growing problem in Hong Kong, with one-quarter of children and adolescents experiencing economic disadvantage. Sixth, youth unemployment and nonengaged youth were emerging problems in the past two decades. Seventh, family and parenting problems in families with adolescents deserve our attention and the Social Development Index showed that there was a gradual drop in family solidarity in the past decade. Because the review by Shek [1] was carried out a few years ago, there is a need to review those adolescent developmental problems that deserve the attention of policymakers, service providers, and academics. An overview of adolescent developmental problems also provides useful pointers to determine priority areas for the development of adolescent prevention and positive youth development programs.

\section{ADOLESCENT SUBSTANCE ABUSE}

Internationally, a survey of the websites of several international organizations (e.g., Office on Drugs and Crime of the United Nations, International Narcotics Control Board, National Institute of Drug Abuse in the United States, and European Monitoring Center for Drugs and Drug Addiction) shows that illicit drug use is a thorny global problem to be resolved. Probably because of the influence of popular culture and youth subculture, substance abuse among young people has also become an acute global problem. As Hong Kong is an international city where information flow (including those related to psychotropic drugs) is very quick, adolescent substance abuse is also a grave concern for Hong Kong [2].

An examination of the substance abuse figures in the past twenty years showed that there were three peaks in the substance abusers figures reported to the Central Registry of Drug Abuse (CRDA) maintained by the Narcotics Division of the Government. As shown in Table 1, the first peak was in mid-1990s which was mainly related to easy access to tranquilizers which were not tightly controlled by legislations. The second peak was in the early 2000s which was closely related to the rave party culture. The third peak was in 2008-2009 which was mainly related to ketamine abuse in schools. In fact, these peaks mirrored the global trend of abusing nonopiate psychotropic substances and the growing belief among young people that psychotropic substance abuse is nonaddictive and it is a valid choice of life. As shown in Table 2, the number of young people abusing psychotropic substances has increased in the past decade. In the recent 
TABLE 1: Trends of substance abuse in Hong Kong based on the Central Registry on Drug Abuse.

\begin{tabular}{|c|c|c|c|c|c|c|c|c|c|c|c|}
\hline & 1999 & 2000 & 2001 & 2002 & 2003 & 2004 & 2005 & 2006 & 2007 & 2008 & 2009 \\
\hline \multicolumn{12}{|l|}{ All reported drug abusers } \\
\hline No. & 16,314 & 18,335 & 18,513 & 17,966 & 15,790 & 14,854 & 14,115 & 13,252 & 13,593 & 14,241 & 13,909 \\
\hline Mean age & 35 & 32 & 32 & 34 & 34 & 35 & 35 & 34 & 34 & 33 & 33 \\
\hline Male & 14,147 & 15,355 & 15,640 & 14,780 & 13,272 & 12,200 & 11,449 & 10,706 & 11,127 & 11,334 & 11,161 \\
\hline$\%$ of all & 86.7 & 83.7 & 84.5 & 82.3 & 84.1 & 82.1 & 81.1 & 80.8 & 81.9 & 79.6 & 80.2 \\
\hline Mean age & 36 & 34 & 34 & 35 & 36 & 36 & 37 & 36 & 35 & 35 & 35 \\
\hline Female & 2,167 & 2,980 & 2,873 & 3,186 & 2,518 & 2,654 & 2,666 & 2,546 & 2,466 & 2,907 & 2,748 \\
\hline$\%$ of all & 13.3 & 16.3 & 15.5 & 17.7 & 15.9 & 17.9 & 18.9 & 19.2 & 18.1 & 20.4 & 19.8 \\
\hline Mean age & 28 & 25 & 26 & 27 & 28 & 28 & 28 & 27 & 28 & 27 & 27 \\
\hline Young persons aged under 2 & 12,482 & 4,020 & 3,902 & 3,002 & 2,207 & 2,186 & 2,278 & 2,578 & 2,999 & 3,473 & 3,359 \\
\hline$\%$ of all & 15.2 & 21.9 & 21.1 & 16.7 & 14.0 & 14.7 & 16.1 & 19.5 & 22.1 & 24.4 & 24.1 \\
\hline Mean age & 18 & 17 & 17 & 17 & 17 & 17 & 17 & 17 & 17 & 17 & 17 \\
\hline Newly reported persons & 3,135 & 5,395 & 5,644 & 5,241 & 4,444 & 3,760 & 3,725 & 3,517 & 4,180 & 4,625 & 4,396 \\
\hline$\%$ of all & 19.2 & 29.4 & 30.5 & 29.2 & 28.1 & 25.3 & 26.4 & 26.5 & 30.8 & 32.5 & 31.6 \\
\hline Mean age & 25 & 23 & 23 & 24 & 25 & 24 & 23 & 23 & 23 & 23 & 23 \\
\hline
\end{tabular}

Source: Narcotics Division, Central Registry of Drug Abuse Fifty-ninth Report: 2000-2009, Narcotics Division, Security Bureau, Hong Kong Special Administrative Region, 2010 and Narcotics Division, Central Registry of Drug Abuse Fifty-eighth Report: 1999-2008, Narcotics Division, Security Bureau, Hong Kong Special Administrative Region, 2009.

school survey conducted by the Narcotics Division, Government of the Hong Kong Special Administrative Region, it was found that drug abuse was more prevalent than those reported in previous studies, although the prevalence rates were still not as high as those in western countries (Tables 3 and 4).

Based on the CRDA figures and school survey findings, there are several additional observations that deserve our attention. First, as shown in Tables 1 and 2, drugs abused by young people under the age of 21 were mainly psychotropic substances, particularly ketamine. Actually, ketamine abuse in Hong Kong could be regarded as quite unique because this drug is not commonly abused in other parts of the world. Second, with the return of Hong Kong to China in 1997, traveling between Hong Kong and Shenzhen in mainland China has become very popular, hence creating the problem of cross-border adolescent substance abuse. Actually, with the use of electronic home-return permits, adolescents can easily go to Shenzhen to abuse drugs without leaving any trace in their travel documents. Hence, it is extremely difficult for parents to know whether their children have gone to Shenzhen from Hong Kong. Third, as the Hong Kong police force has stepped up action against adolescent substance abuse in rave parties, the venues of drug abuse among young people has become more diversified. Actually, some research studies showed that adolescents abused drugs in their homes, an emerging trend that deserves our attention. Fourth, as the price of ketamine is low and it is easy to consume the drug, abusers are not easily identified in their appearance and addictive behavior. Finally, based on the data from the CRDA, peer influence and curiosity are major perceived factors leading to adolescent substance abuse (Table 5).

\section{INTERNET ADDICTION}

Several prevalence studies on Internet addiction have been carried out in Hong Kong. Utilizing the Young's 20-item questionnaire to examine Internet addiction among 976 students, Tsuen Wan Centre of the Chinese YMCA of Hong Kong [3] found that $61.4 \%$ of senior primary school students, $35.2 \%$ of Secondary 1 to Secondary 3 students, $18.8 \%$ of Secondary 4 to Secondary 5 students, $35.8 \%$ of Secondary 6 to Secondary 7 students, and $37.0 \%$ of college students could be identified as highly at risk of Internet addiction. By comparing the data derived from two studies using the Young's 8-item questionnaire, Chan [4] found that 
TABLE 2: Reported drug abusers by type of drugs abused based on the Central Registry on Drug Abuse.

\begin{tabular}{|c|c|c|c|c|c|c|c|c|c|c|c|}
\hline \multirow{2}{*}{ Age group/type of drugs abused } & \multicolumn{11}{|c|}{ No. of persons $(\%)$} \\
\hline & 1999 & 2000 & 2001 & 2002 & 2003 & 2004 & 2005 & 2006 & 2007 & 2008 & 2009 \\
\hline \multicolumn{12}{|l|}{ Aged under 21} \\
\hline \multirow{2}{*}{ Opiates } & 1,089 & 749 & 428 & 267 & 137 & 112 & 87 & 53 & 62 & 62 & 79 \\
\hline & $(49.1)$ & $(21.6)$ & $(13.3)$ & $(10.7)$ & $(7.5)$ & $(5.3)$ & (3.9) & $(2.1)$ & $(2.1)$ & (1.8) & $(2.4)$ \\
\hline \multirow{2}{*}{ Heroin } & 1,089 & 747 & 426 & 266 & 137 & 112 & 85 & 51 & 62 & 62 & 78 \\
\hline & $(49.1)$ & $(21.5)$ & $(13.3)$ & $(10.7)$ & $(7.5)$ & (5.3) & (3.8) & $(2.0)$ & $(2.1)$ & (1.8) & (2.3) \\
\hline \multirow{2}{*}{ Opium } & - & - & - & @ & - & - & - & - & - & - & - \\
\hline & $(-)$ & $(-)$ & $(-)$ & (@) & $(-)$ & $(-)$ & $(-)$ & $(-)$ & $(-)$ & $(-)$ & $(-)$ \\
\hline \multirow{2}{*}{ Morphine } & - & @ & @ & - & - & - & - & @ & - & - & - \\
\hline & $(-)$ & (@) & (@) & $(-)$ & $(-)$ & $(-)$ & $(-)$ & (@) & $(-)$ & $(-)$ & $(-)$ \\
\hline \multirow{2}{*}{ Physeptone/Methadone } & 6 & 6 & @ & - & - & @ & - & - & - & @ & @ \\
\hline & $(0.3)$ & $(0.2)$ & (@) & $(-)$ & $(-)$ & (@) & $(-)$ & $(-)$ & $(-)$ & (@) & (@) \\
\hline \multirow{2}{*}{ Psychotropic substances } & 1,289 & 2,845 & 2,863 & 2,276 & 1,722 & 2,052 & 2,185 & 2,525 & 2,948 & 3,423 & 3,296 \\
\hline & $(58.1)$ & $(82.1)$ & $(89.2)$ & $(91.2)$ & $(94.0)$ & $(96.5)$ & $(97.5)$ & $(99.0)$ & $(99.0)$ & $(98.8)$ & $(98.9)$ \\
\hline \multirow{2}{*}{ Ketamine } & 14 & 1,280 & 1,919 & 1,757 & 1,153 & 1,480 & 1,368 & 1,876 & 2,392 & 2,961 & 2,809 \\
\hline & $(0.6)$ & $(36.9)$ & $(59.8)$ & $(70.4)$ & $(62.9)$ & $(69.6)$ & $(61.1)$ & $(73.5)$ & $(80.3)$ & $(85.5)$ & $(84.3)$ \\
\hline \multirow{2}{*}{ Triazolam/Midazolam/Zopiclone } & 34 & 42 & 30 & 34 & 92 & 92 & 82 & 67 & 52 & 36 & 42 \\
\hline & $(1.5)$ & $(1.2)$ & $(0.9)$ & (1.4) & $(5.0)$ & $(4.3)$ & (3.7) & $(2.6)$ & $(1.7)$ & $(1.0)$ & (1.3) \\
\hline \multirow{2}{*}{ Amphetamines } & 647 & 2,148 & 1,904 & 1,039 & 722 & 907 & 1,325 & 1,261 & 955 & 963 & 892 \\
\hline & $(29.2)$ & $(62.0)$ & $(59.3)$ & $(41.6)$ & $(39.4)$ & $(42.6)$ & $(59.2)$ & $(49.4)$ & $(32.1)$ & $(27.8)$ & $(26.8)$ \\
\hline \multirow{2}{*}{ MDMA (Ecstasy) } & 290 & 1,949 & 1,701 & 928 & 635 & 814 & 1,194 & 1,088 & 631 & 540 & 397 \\
\hline & $(13.1)$ & $(56.2)$ & $(53.0)$ & $(37.2)$ & $(34.7)$ & $(38.3)$ & $(53.3)$ & $(42.6)$ & $(21.2)$ & $(15.6)$ & $(11.9)$ \\
\hline \multirow{2}{*}{ Methylamphetamine (Ice) } & 383 & 381 & 348 & 204 & 124 & 143 & 180 & 264 & 407 & 516 & 554 \\
\hline & $(17.3)$ & $(11.0)$ & $(10.8)$ & $(8.2)$ & $(6.8)$ & (6.7) & (8.0) & $(10.3)$ & $(13.7)$ & $(14.9)$ & $(16.6)$ \\
\hline \multirow{2}{*}{ Cannabis } & 671 & 736 & 557 & 647 & 524 & 543 & 572 & 475 & 363 & 312 & 247 \\
\hline & $(30.2)$ & $(21.2)$ & $(17.4)$ & $(25.9)$ & $(28.6)$ & $(25.5)$ & $(25.5)$ & $(18.6)$ & $(12.2)$ & $(9.0)$ & (7.4) \\
\hline \multirow{2}{*}{ Cocaine } & 6 & 9 & 12 & 14 & 10 & 20 & 58 & 170 & 356 & 326 & 218 \\
\hline & $(0.3)$ & $(0.3)$ & $(0.4)$ & $(0.6)$ & $(0.5)$ & $(0.9)$ & (2.6) & $(6.7)$ & $(12.0)$ & $(9.4)$ & $(6.5)$ \\
\hline \multirow{2}{*}{ Cough medicine } & 100 & 90 & 44 & 79 & 142 & 205 & 216 & 178 & 132 & 107 & 125 \\
\hline & (4.5) & (2.6) & (1.4) & (3.2) & $(7.8)$ & (9.6) & (9.6) & $(7.0)$ & $(4.4)$ & (3.1) & (3.8) \\
\hline \multirow{2}{*}{ Nimetazepam } & - & - & 11 & 44 & 31 & 120 & 152 & 343 & 273 & 227 & 183 \\
\hline & $(-)$ & $(-)$ & $(0.3)$ & $(1.8)$ & $(1.7)$ & $(5.6)$ & (6.8) & (13.4) & $(9.2)$ & (6.6) & (5.5) \\
\hline \multirow{2}{*}{ Diazepam } & 44 & 78 & 19 & 36 & 17 & 12 & 8 & @ & 7 & 10 & @ \\
\hline & $(2.0)$ & $(2.2)$ & $(0.6)$ & (1.4) & $(0.9)$ & $(0.6)$ & $(0.4)$ & (@) & $(0.2)$ & $(0.3)$ & (@) \\
\hline \multirow{2}{*}{ Organic solvents } & 100 & 61 & 48 & 65 & 52 & 29 & 27 & 12 & 10 & - & @ \\
\hline & $(4.5)$ & (1.8) & (1.5) & (2.6) & $(2.8)$ & (1.4) & (1.2) & $(0.5)$ & $(0.3)$ & $(-)$ & (@) \\
\hline \multirow{2}{*}{ Methaqualone } & @ & 12 & $@$ & 9 & 12 & 17 & 25 & 24 & 13 & 23 & 12 \\
\hline & (@) & $(0.3)$ & (@) & $(0.4)$ & $(0.7)$ & $(0.8)$ & (1.1) & $(0.9)$ & $(0.4)$ & $(0.7)$ & $(0.4)$ \\
\hline Sub-total & 2,219 & 3,467 & 3,210 & 2,496 & 1,832 & 2,127 & 2,240 & 2,551 & 2,979 & 3,463 & 3,332 \\
\hline
\end{tabular}


TABLE 3: Proportion of lifetime drug-taking students by age and by sex (Secondary Students) based on 2008/09 survey of drug use among students.

\begin{tabular}{lcc}
\hline Age/sex & $2004 / 2005(\%)$ & $2008 / 2009(\%)$ \\
\hline Age & & \\
12 or below & 2.4 & 4.6 \\
13 & 3.0 & 4.5 \\
14 & 3.4 & 4.4 \\
15 & 3.2 & 4.8 \\
16 & 3.5 & 4.2 \\
17 & 4.0 & 4.3 \\
18 & 3.2 & 3.4 \\
19 or above & 3.4 & 2.9 \\
\hline Overall & 3.3 & 4.3 \\
\hline Sex & & \\
Male & 3.3 & 4.6 \\
Female & 2.9 & 3.7 \\
\hline Overall & 3.3 & 4.3 \\
\hline
\end{tabular}

Note. Percentages are calculated based on secondary students in the respective age/sex groups who had provided relevant information. Source: Narcotics Division, The 2008/09 Survey of Drug Use among Students, Narcotics Division, Security Division, Hong Kong Special Administrative Region, 2010.

TABLE 4: Proportion of 30-day drug-taking students by age and by sex (Secondary Students) based on 2008/09 survey of drug use among students.

\begin{tabular}{lcc}
\hline Age/sex & $2004 / 2005(\%)$ & $2008 / 2009(\%)$ \\
\hline Age & & \\
12 or below & 0.5 & 1.5 \\
13 & 0.5 & 1.4 \\
14 & 1.0 & 1.7 \\
15 & 1.0 & 1.8 \\
16 & 0.9 & 1.3 \\
17 & 1.1 & 1.6 \\
18 & 0.6 & 1.2 \\
19 or above & 0.6 & 0.9 \\
\hline Overall & 0.8 & 1.5 \\
\hline Sex & & \\
Male & 0.8 & 1.6 \\
Female & 0.7 & 1.2 \\
\hline Overall & 0.8 & 1.5 \\
\hline
\end{tabular}

Note. Percentages are calculated based on secondary students in the respective age/sex groups who had provided relevant information.

Source: Narcotics Division, The 2008/09 Survey of Drug Use among Students, Narcotics Division, Security Division, Hong Kong Special Administrative Region, 2010.

the prevalence of Internet addiction had increased from 3.0\% in 2000 to $14.7 \%$ in 2002. In another study of 1,182 adolescents, Yip and Kwok [5] used the modified Young's 8-item questionnaire which showed 5.4\% of the respondents as online game addicts.

There are also research findings showing that adolescents experienced the negative impact of Internet addictive behaviors. For example, in a study of 1,716 Secondary 1 to Secondary 3 students, Against Child 
TABLE 5: Reported drug abusers for 1999-2009 by age group by reason for current drug use based on the Central Registry on Drug Abuse.

\begin{tabular}{|c|c|c|c|c|c|c|c|c|c|c|c|}
\hline Age group/reason for current drug use & 1999 & 2000 & 2001 & 2002 & $\begin{array}{c}2003 \\
\%\end{array}$ & 2004 & 2005 & 2006 & 2007 & 2008 & 2009 \\
\hline \multicolumn{12}{|l|}{ Aged under 21} \\
\hline Peer influence/to identify with peers & 62.8 & 68.2 & 66.0 & 58.2 & 57.9 & 60.0 & 68.4 & 64.9 & 58.8 & 64.2 & 67.7 \\
\hline Relief of boredom/depression/anxiety & 29.8 & 28.2 & 26.4 & 27.6 & 28.7 & 31.4 & 40.4 & 41.3 & 41.3 & 44.2 & 51.1 \\
\hline Avoid discomfort of its absence & 28.8 & 13.4 & 9.3 & 7.8 & 6.6 & 6.6 & 7.3 & 8.9 & 12.7 & 16.3 & 15.2 \\
\hline Curiosity & 35.7 & 42.9 & 43.4 & 38.6 & 38.2 & 41.0 & 35.8 & 41.1 & 42.7 & 45.1 & 43.0 \\
\hline To seek euphoria or sensory satisfaction & 26.5 & 44.5 & 39.6 & 38.9 & 32.7 & 34.6 & 43.4 & 42.4 & 37.4 & 33.9 & 33.6 \\
\hline For self-medication & 1.3 & 0.6 & 0.8 & 0.5 & 1.6 & 0.8 & 1.3 & 1.3 & 1.2 & 1.6 & 2.0 \\
\hline Under influence of the partner & 3.0 & 2.3 & 1.9 & 2.0 & 2.4 & 1.6 & 3.7 & 4.6 & 4.2 & 5.4 & 5.6 \\
\hline Other reasons & 4.2 & 2.1 & 0.7 & 0.8 & 0.5 & 0.3 & 0.8 & 1.1 & 0.7 & 0.3 & 0.1 \\
\hline
\end{tabular}

Source: Narcotics Division, Central Registry of Drug Abuse Fifty-ninth Report: 2000-2009, Narcotics Division, Security Bureau, Hong Kong Special Administrative Region, 2010 and Narcotics Division, Central Registry of Drug Abuse Fifty-eighth Report: 1999-2008, Narcotics Division, Security Bureau, Hong Kong Special Administrative Region, 2009.

Abuse [6] found that $37 \%$ of the respondents admitted that they "could not resist the attraction from being online" and $28.5 \%$ of the respondents agreed that "online activities largely affected their normal daily lives". Similarly, in a study of 677 pairs of parent-child, Choi et al. [7] found that $14.5 \%$ of the parent respondents often had conflicts with their children regarding Internet use.

In the study conducted by Shek et al. [8], Internet addiction behavior was examined in 6,121 Chinese primary and secondary school students in Hong Kong based on the assessment frameworks developed by Ivan Goldberg and Kimberly Young. The result showed that scales derived from both frameworks (CIAYoung Scale and CIA-Goldberg Scale) were internally consistent and evidence supporting their validity was found. Descriptive statistical analyses revealed that roughly one-fifth of the respondents could be classified as Internet addicted based on either scale. Further analyses showed that Internet-addicted and Internet-nonaddicted respondents differed in Internet use and related behavior (see Tables 6 and 7). Logistic regression analyses showed that engagement in certain online activities (such as playing online games and downloading software) and replacement of pastimes activities (such as watching TV and going out with friends) by Internet activities predicted higher probability of Internet addiction.

In another study, Shek et al. [9] reported an evaluation study of an indigenous multilevel counseling program designed for young people with Internet addiction problem based on the responses of 59 clients. By using the ecological perspective, the basic intervention model posited that adolescent Internet addiction was a consequence of problems at the individual (e.g., false beliefs), interpersonal (e.g., peer influence), family (e.g., loose parenting), and community (e.g., Internet addiction culture) levels. Regarding objective outcome evaluation, pretest and posttest data generally showed that the Internet addiction problems of the participants decreased after joining the program and there were some slight positive changes in the parenting attributes. For the subjective outcome evaluation findings, the participants generally perceived that the program was helpful to them. Findings based on these two evaluation strategies suggest that this multilevel indigenous counseling program involving individual, peers, and family intervention has promise to help young people with Internet addiction problems.

\section{ADOLESCENT SEXUALITY ISSUE}

In the area of sexuality, the rates of students having premarital sex have increased [10]. For adolescent students studying in Secondary 3 to Secondary 7, rates of adolescent boys having premarital sex were 1.2, 5.6 and $8.7 \%$ in 1991, 1996, and 2001, respectively, and the corresponding figures were $0.2,4.5$, and 5.2 
TABLE 6: Percentages of responses to the questions in CIA-Goldberg [8].

\begin{tabular}{|c|c|c|c|c|}
\hline \multirow{2}{*}{ Criterion } & \multirow{2}{*}{ Question } & \multirow{2}{*}{$N$} & \multicolumn{2}{|c|}{$\%$} \\
\hline & & & Yes & No \\
\hline \multirow[t]{2}{*}{ (1) } & $\begin{array}{l}\text { (a) Do you find there is a diminished effect with continued use of the same } \\
\text { time spent on the Internet? }\end{array}$ & 6,106 & 13.3 & 86.7 \\
\hline & $\begin{array}{l}\text { (b) Do you experience a tolerance in that you have a need for increased } \\
\text { amounts of Internet use to achieve the desired effect? }\end{array}$ & 6,121 & 21.9 & 78.1 \\
\hline (2) & $\begin{array}{l}\text { Do you access Internet more often or for longer periods of time than you } \\
\text { intended? }\end{array}$ & 6,102 & 32.2 & 67.8 \\
\hline (3) & $\begin{array}{l}\text { Have you had a persistent desire or made unsuccessful efforts to cut down } \\
\text { or control the amount of time spend online? }\end{array}$ & 6,081 & 16.4 & 83.6 \\
\hline (4) & $\begin{array}{l}\text { Do you spend a great deal of time in activities related to Internet use (e.g., } \\
\text { buying Internet books, trying out new WWW browsers, organizing files of } \\
\text { downloaded materials)? }\end{array}$ & 6,102 & 26.6 & 73.4 \\
\hline (5) & $\begin{array}{l}\text { Have you given up or reduced any important social, occupational, } \\
\text { academic or recreational activities because of the Internet use? }\end{array}$ & 6,099 & 18.0 & 82.0 \\
\hline (6) & $\begin{array}{l}\text { Have you continued to use the Internet despite knowledge of having } \\
\text { physical, social, occupational, academic or psychological problem (e.g., } \\
\text { sleep deprivation, interpersonal conflicts, lateness for work, lateness for } \\
\text { school, neglect of student or occupational duties)? }\end{array}$ & 6,102 & 18.1 & 81.9 \\
\hline \multirow[t]{10}{*}{ (7) } & $\begin{array}{l}\text { (a) Have you made attempts to cut down the excessive amount of time you } \\
\text { spent online? }\end{array}$ & 5,942 & 42.4 & 57.6 \\
\hline & $\begin{array}{l}\text { (b) Have the following condition been developed within several days to a } \\
\text { month after you made attempts to cut down the excessive amount of time } \\
\text { you spent online? }\end{array}$ & & & \\
\hline & (i) I have had psychomotor agitation. & 5,751 & 6.0 & 94.0 \\
\hline & (ii) I have felt anxious. & 5,751 & 3.0 & 97.0 \\
\hline & (iii) I have had obsessive thinking about what is happening on Internet. & 5,751 & 9.9 & 90.1 \\
\hline & (iv) I have had fantasies or dreams about Internet. & 5,751 & 6.0 & 94.0 \\
\hline & (v) My fingers have done typing movements voluntarily or involuntarily. & 5,751 & 2.1 & 97.9 \\
\hline & $\begin{array}{l}\text { (c) Have you used the Internet as a way of relieving or avoiding the above } \\
\text { unwell condition? }\end{array}$ & 5,745 & 4.8 & 95.2 \\
\hline & $\begin{array}{l}\text { (d) Do you feel that the above conditions cause distress or impairment in } \\
\text { your social, occupational or another important area of functioning? }\end{array}$ & 5,718 & 4.3 & 95.7 \\
\hline & verall "Internet Addicted" Percentage (met 3 or more criteria) & 6,000 & 22.9 & 77.1 \\
\hline
\end{tabular}

for adolescent girls. For adolescents aged 18-27, the related figures were 36.7, 39.8, and 44.9 in adolescent boys and 32.7, 39.4, and 35.2 for adolescent girls. Furthermore, there are research findings showing that sexual attitudes of adolescents in Hong Kong have become more liberal with $49.6 \%$ endorsed premarital sex and $47.7 \%$ perceived that abortion was acceptable. The increasing trend of the above figures indicates that the Hong Kong society will face a number of adolescent problems (e.g., teenage pregnancy and sexually transmitted diseases) shortly, and the best way to reverse the trend or lower the increasing rate is the longterm quality education, especially the implementation of quality sex education in schools.

The link between sex and love tends to be quite weak. Many youths approve of sexual intercourse without love [11]. In other words, sex is regarded as a recreational activity-an activity for enjoyment and happiness. On the other hand, celibacy or sexual abstinence (i.e., refraining from sexual intercourse) is perhaps an effective method for preventing the disturbed consequences arising from adolescent sexual 
TABLE 7: Percentages of responses to the questions in CIA-Young [8].

\begin{tabular}{|c|c|c|c|c|}
\hline & \multirow{2}{*}{ Question } & \multirow{2}{*}{$N$} & \multicolumn{2}{|c|}{$\%$} \\
\hline & & & Yes & No \\
\hline (1) & $\begin{array}{l}\text { Do you feel preoccupied with the Internet or online services and think about it } \\
\text { while offline? }\end{array}$ & 6,118 & 25.2 & 74.8 \\
\hline (2) & Do you feel a need to spend more and more time online to achieve satisfaction? & 6,121 & 21.9 & 78.1 \\
\hline (3) & $\begin{array}{l}\text { Have you repeatedly made unsuccessful efforts to control, cut back, or stop } \\
\text { Internet use? }\end{array}$ & 6,104 & 17.6 & 82.4 \\
\hline (4) & $\begin{array}{l}\text { Do you feel restless, moody, depressed, or irritable when attempting to cut } \\
\text { down or stop Internet use? }\end{array}$ & 6,106 & 12.3 & 87.7 \\
\hline (5) & Do you stay online longer than original intended? & 6,118 & 41.4 & 58.6 \\
\hline (6) & $\begin{array}{l}\text { Have you jeopardized or risked the loss of significant relationship, job, } \\
\text { educational or career opportunity because of the Internet? }\end{array}$ & 6,114 & 22.5 & 77.5 \\
\hline (7) & $\begin{array}{l}\text { Have you lied to family members, teachers, social workers, or others to conceal } \\
\text { the extent of involvement with the Internet? }\end{array}$ & 6,102 & 11.3 & 88.7 \\
\hline (8) & $\begin{array}{l}\text { Do you use the Internet as a way of escaping from problems or of relieving a } \\
\text { dysphoric mood (e.g., feelings of helplessness, guilt, anxiety, depression)? }\end{array}$ & 6,105 & 12.0 & 88.0 \\
\hline (9) & Do you keep returning even after spending too much money on online fees? & 6,103 & 15.9 & 84.1 \\
\hline$(10)$ & Do you feel depressed, irritable, moody or anxious when you are offline? & 6,114 & 11.2 & 88.8 \\
\hline \multicolumn{2}{|r|}{ Overall "Internet Addicted" Percentage (answered "Yes" to 4 or more questions) } & 6,024 & 19.1 & 80.9 \\
\hline
\end{tabular}

intercourse, for example, teenage pregnancy. "Most health experts recommend that teenagers practice sexual abstinence before marriage" [12, page 89]. It is important to understand the reasons why the adolescents choose to be remaining abstinent. There are four common reasons for sexual abstinence [12, 13]: (1) fear of pregnancy: most adolescents understand that sexual intercourse may cause pregnancy and they also know to some extent that the consequence of pregnancy during their school age is serious and detrimental to their school life; (2) fear of sexually transmitted diseases (STDs): adolescents are concerned about suffering from STDs when they have sex. Unfortunately adolescents are at high risk of acquiring STDs because they have "limited access to preventive and regular health care and physiologically increased susceptibility to infection" [14, page 2]; (3) moral and/or religious beliefs: the general beliefs in the society prescribe that sex should be practiced until marriage, and it is not right to have sex in their age; (4) parents' objection: parents' attitudes and objections to premarital sex do have a significant effect on the adolescents' sexual behavior [13].

Similar to other behaviors, peers exert great influence on the sexual behavior of adolescents $[15,16]$. In a study of the peer influence on sexual behavior in African-American adolescents, Leigh and Andrews [16] concluded that adolescents "whose peers exhibit negative behaviors (such as substance use and school truancy) are more likely to engage in high-risk sexual behaviors" [16, page 8]. In a study of the relation between the peer relationships and social behavior, Ma et al. [17] found that "antisocial adolescents tended to perceive their best friend as antisocial and exerting more negative influences on them, whereas prosocial adolescents tended to perceive their best friend as prosocial and exerting more positive influences on them" [17, page 255]. The possible peer influences on adolescent sexual behavior should always be one of the major focuses of parents and educators in the education of the younger generation.

Another important sex issue is the homosexual behavior and identity or the sexual orientation in adolescence [18]. A number of points should be noted. (1) It is estimated that about 5 to $10 \%$ of the adult population is gay, lesbian, or bisexual. (2) Research indicated that both the genetic and environmental factors contribute to the development of homosexuality. (3) Many homosexual or bisexual adolescents experienced 
difficulties in accepting this identity and may try hard to ignore such sentiments [19]. This is one of the most sensitive issues that we need to carefully deal with in the education in schools.

\section{SCHOOL BULLYING}

There are basically two types of aggression in adolescents: physical aggression which includes fighting, hitting, and physical assault and relational aggression which is an action that affects adversely the victim's interpersonal relationships with others [19, page 472]. In a study of physical bullying (slapping, fist-fighting, hitting and assault) in Hong Kong schools, Wong [20] found that $17.2 \%$ of the secondary school sample admitted bullying other students while $18.3 \%$ were the victims of physical bullying in the last six months. In addition, $58.6 \%$ of the sample was involved in the bullying as bystanders. The situation is even more serious in Wong's primary school sample. The main characteristics of the typical bullies are as follows; (1) poor perspective-taking abilities: the bullies are less able to perceive matters from other's perspective or to empathize with the victims; (2) impulsivity, hyperactivity, domination, and overreaction: the bullies tend to be impulsive in their action and less thoughtful; they have a strong need to dominate over others; and they are usually hyperactive and often overreact to other's behaviors especially those behaviors that have ambiguous meanings; (3) belief about the appropriateness and effectiveness of aggression: the bullies share with a small group of friends a common belief of violence value. They believe in the effectiveness of aggression and think that violence can solve all the daily problems and conflicts; (4) poor social relationships: the bullies usually experience negative peer relations and negative teacher relations; (5) low academic achievement: the bullies tend to have low academic achievement in school; (6) poor family social environment: the bullies usually come from a negative family social environment - a family that is less cohesive, less warm and often has a lot of conflicts among family members [20,21]. There are two types of victims. The first type is passive victim who seldom resist to the bullies and would not react aggressively to the bullies. They tend to be more anxious, less dominating and less assertive than the average adolescents. The second type is reactive victim who usually react aggressively and will make revenge and attack the bullies right away. These victims tend to be emotional and have bad temperament. In addition, both types of victims have the following characteristics: (1) They are lonely adolescents, often rejected by peers; (2) They are usually overprotected by their parents; (3) They have low self-esteem [20, 21].

Research and surveys indicated that the rate of bullying tends to rise in recent years and there are some useful and practical suggestions proposed by researchers and educators [20-23]. (1) A wholeperson curriculum should be constructed and implemented in schools as early as possible [21]. (2) In an intervention study, Wurf [22] found that the school that employed whole-school approach in preventing the school bullying has demonstrated the best effect in lowering the rate of bullying. Ma [23] also advocates the whole-school approach in his proposal for preventing school bullying. (3) Wong [20] argued that "a comprehensive anti-bullying strategy such as assisting students to develop adequate self-competency, strong social skills, and good relationships with parents and teachers seems to be a useful anti-violence strategy" [20, pages 548-549]. In other words, the teaching of positive youth development constructs is a useful strategy to prevent school bullying in the long run.

\section{MATERIAL ORIENTATION}

Overemphasis on money and material possession is another concern for adolescents. Commission on Youth [24] conducted a comprehensive study on the civic awareness and moral values of young people in Hong Kong. Their findings showed that the majority of young people endorsed values in the areas of benevolence, universalism, tradition, and conformity, and they valued family, friendship, honesty, responsibility, and peace of mind, but a significant proportion of youths (20 to 30\%) had material orientations based on wealth, hedonism, and sensual stimulation and they would use unethical means to achieve their ends.

In the socialization of Chinese children, parents tend to place great emphasis on obedience, proper behavior, and high academic achievement $[25,26]$. The argument is that, if you behave yourself and if 
you can get very good examination results, you will be able to enter into a good university. With a good university degree, you will then be able to get a good job and earn a lot of money. The concept of success held by parents is quite instrumental and often materialistic. Nevertheless, the parental influences on the development of the concept of money and material orientation in adolescents are tremendous. In addition, Hong Kong is an international society with an emphasis on finance and economics. It is no wonder that a substantial percentage of youths in Hong Kong had material orientation based on wealth.

More disturbing is that some of them would consider using unethical means to achieve their wealth. One current social phenomenon that attracts the attention of educators is the practice of compensated dating by teenage girls. Compensated dating means that young girls serve as companion of older men who will give them money or luxury gifts. In some senses, compensated dating is regarded as a kind of prostitution, and in some cases, young boys are involved. In a survey of 586 young people aged 12 to 20 conducted by Hong Kong Christian Service [27], 34\% of the participants indicated that they would consider offering compensated dating and 57\% of these participants said that they would do it for the sake of earning quick cash. There are two important implications of this survey finding: (1) A very high proportion of young people would consider offering compensated dating. It seems that many of our younger generation do not regard selling sex is unethical or unacceptable. (2) They regard compensated dating as an easy and fast way for earning money. Does it mean that any ways that will help them earn money easily and quickly is regarded as good and acceptable? The situation appears to be quite alarming. The development of a positive concept of money and material possession as well as a positive concept of success is definitely one of the major concerns of educators, teachers and parents.

\section{THE QUEST FOR AN ECOLOGICAL UNDERSTANDING OF ADOLESCENT DEVELOPMENTAL PROBLEMS}

Theoretically, a proper understanding of the issue of adolescent developmental problems is important because explanations for adolescent developmental problems determine the intervention foci. Although adolescent developmental problems can be understood in terms of different perspectives (such as biological, Freudian, neo-Freudian, behavioral, cognitive-behavioral, cognitive, interpersonal, family and sociocultural approaches), the ecological perspective has commonly been used to guide intervention strategies [28]. The basic assertion of ecological models is that human behavior such as adolescent developmental problem is influenced by different personal and environmental factors in different systems. As far as individual factors are concerned, there are views suggesting that personal factors are involved in adolescent developmental problems, such as substance abuse. On the other hand, there are research findings showing that environmental conditions, such as poverty and family ecological processes, are important determinants of adolescent developmental problems. While there are different versions of ecological models, the general thesis underlying different ecological models is that in order to change individual behavior, changes in both the individual (e.g., promoting social and emotional competence) and environment levels (e.g., creating bonding and provision of social opportunities) would be indispensable.

Ecological models are commonly used by researchers in the prevention science and positive youth development fields. For example, in their discussion of the critical issues in the prevention of violence, Kerns and Prinz [29] pointed out that some intervention programs appear to lack a specific theoretical underpinning and "many of these are "feel good" programs with little empirical support justifying program design" (page 139), and they further pointed out that social-ecological contexts and the related mediating and moderating factors should be taken into account. In his attempt to develop a conceptual framework in which conditions linked to positive youth development are described, Granger [30] made an ecological suggestion that strategies that enhance the will or capacity of individuals, organizations, systems, and communities would lead to change. Regarding the different systems, and ecological contexts that could generate changes in adolescents, one important context for creating changes is in the school system, and there are numerous examples in the West that school-based positive youth development programs aiming at promoting psychosocial competencies generated positive changes in students [31]. 
One basic thesis in ecological models is that there are risk and protective factors on different levels that contribute to adolescent risk behavior. There are numerous research studies showing that risk factors at the individual level (e.g., weak psychosocial competencies, meaninglessness), family level (e.g., parental marital discords, nonintact families), school level (e.g., low academic achievement, weak school support) and community level (e.g., growing up in deprived communities, easy accessibility to drugs) increase adolescent risk behavior, such as drug abuse in adolescents [28]. On the other hand, there is also a vast literature showing that there are factors that can reduce the probability of adolescent risk behavior. Research findings showed that adolescents may adjust well despite the presence of adversity [32]. According to Hauser [32], protective factors are "key constructs in conceptualizations of resilience" which "moderate the effects of individual vulnerabilities or environmental hazards, so that a given developmental trajectory reflects more adaptation in a given domain than would be the case if protective processes were not operating" [32, page 4]. Based on a review of the resilience literature, Hauser [32] outlined several categories of protective factors, including individual (e.g., healthy attribution style, self-efficacy, hope, faith), relational (e.g., supportive home environment), community (e.g., good schools and other community assets) and general (e.g., good fortune) protective factors. In a review of stress, coping, and resilience in children and youth, Smith and Carlson [33] similarly suggested that individual factors (e.g., optimism and faith), family factors (e.g., parental support and guidance), and external support systems (e.g., supportive nonparent adults) are important protective factors in children and adolescents experiencing environmental hazards. Utilizing research findings related to risk and protective processes in adolescent risk behavior resilience, developers of positive youth development programs have attempted to reduce the impact of risk factors and to promote the influence of protective factors via the developed programs. Historically, the utilization of risk and protective factors has shaped the "prevention science" perspective [28].

\section{IMPLICATIONS FOR THE DESIGN OF POSITIVE YOUTH DEVELOPMENT PROGRAM}

In the traditional prevention context, identification of the needs and problems of adolescents (e.g., substance abuse, delinquency, suicide) forms the basis of prevention programs where such programs are usually developed with reference to the "problems" and "pathologies" of adolescents. For example, in response to the growing drug abuse problem among young people, preventive substance abuse programs are called for. Of course, it is possible to design adolescent prevention programs with reference to the adolescent developmental problems highlighted in this paper. However, there are many criticisms of this approach, such as the difficulty of developing a prevention program for each adolescent developmental issue and the possible stigmatizing nature of youth prevention programs. Alternatively, positive youth development approach is primarily placed on adolescent developmental assets rather than adolescent problems. According to Catalano et al. [31], there are several attributes of the positive youth development approach. These include, (a) emphasis on integrated youth development (i.e., focusing on a range of youth developmental possibilities and problems) rather than dealing with a single youth problem; (b) upholding the belief that "problem-free is not fully prepared"; (c) emphasis of person-in-environment perspective; and (d) focus on developmental models on how young people grow, learn and change. The underlying assumption of positive youth development programs is that, through strengthening of psychosocial competencies in adolescents, adolescent risk behavior will not be easily developed. This assumption is similar to the belief in Chinese medicine in which it is commonly believed that, with the use of Chinese medicine to strengthen the body, the symptoms of illness will disappear. In terms of prevention of illness, Chinese medical practitioners also believe that through strengthening of the body, it is not easy to develop symptoms.

Theoretically, there are accounts postulating that positive youth development is inversely related to adolescent problem behavior. Based on the concepts of protective factors in resilience literature, it can be conjectured that internal resources such as psychosocial competencies and external resources such as 
bonding [34] would protect individuals from life stresses, thus minimizing the occurrence of problem behavior. There are researches showing that positive youth development was negatively related to problem behavior, such as substance abuse and delinquency. In North America, Catalano et al. [31] showed that around $96 \%$ of the 25 well-evaluated positive youth development programs reduced problem behavior. Evaluative studies of the programs in the field have provided support for the effectiveness of fostering youth developmental assets [35] in reducing problem behaviors [36, 37].

There are also local research findings showing that positive youth development was negatively related to adolescent problem behavior: Shek [38] found that positive youth behavior was negatively related to behavioral intention to engage in problem behavior among Chinese adolescents; Sun and Shek [39] showed that positive youth development was negatively related to adolescent problem behavior at a single time point; Sun and Shek [40] further showed that positive youth development negatively predicted adolescent problem behavior over time.

With reference to the intensification of adolescent developmental problems in Hong Kong, there are very few systematic and multiyear positive youth development programs in Hong Kong [41]. For the existing youth enhancement programs, they commonly deal with isolated problems and issues in adolescent development (i.e., deficits-oriented programs), and they are relatively short term in nature. To promote holistic development among adolescents in Hong Kong, The Hong Kong Jockey Club Charities Trust initiated and launched a project entitled "P.A.T.H.S. to Adulthood: A Jockey Club Youth Enhancement Scheme." The word "P.A.T.H.S." denotes Positive Adolescent Training through Holistic Social Programmes. The Trust invited academics of five universities in Hong Kong to form a research team with The Hong Kong Polytechnic University as the lead institution to develop a multiyear universal positive youth development program to promote holistic adolescent development in Hong Kong, with an earmarked grant of HK $\$ 400$ million for the original phase. There are two tiers of programs (Tier 1 and Tier 2 Programs) in this project. Tier 1 Program is a universal positive youth development program, where students in Secondary 1 to Secondary 3 participate in the program, normally with 20 hours of training in the school year at each grade. On the other hand, Tier 2 Program is generally provided for at least one-fifth of the students who have greater psychosocial needs at each grade (i.e., selective program).

Because of the positive evaluation findings associated with the original phase, the Trust earmarked an additional HK\$350 million to revamp the existing curriculum and to develop new units with specific reference to the adolescent developmental problems highlighted in this paper. The development of the 60 new units will be carried out with reference to the five adolescent developmental problems highlighted in this paper. The structure of the new units to be developed, together with the underlying rationales underlying the development of the new units and the teaching strategies, will be described in another separate paper in this special issue. Consistent with the philosophy of positive youth development, it is argued that promotion of psychosocial competencies in the program participants via curriculum-based school programs will lead to a reduction of adolescent problem behavior in the long run. Actually, there are evaluation findings showing that the program was effective in promoting adolescent development and reducing adolescent problem behavior [42-44].

Nevertheless, it is noteworthy that focusing on the importance of psychosocial competencies does not imply that environmental factors are not important. Within the scope of Tier 1 Program of the Project P.A.T.H.S., the primary focus will be put on the promotion of psychosocial competencies of the program participants via curriculum-based programs. On the other hand, changes in the environmental factors may possibly be carried out in Tier 2 program of the project.

\section{ACKNOWLEDGMENT}

The preparation for this paper and the Project P.A.T.H.S. were financially supported by The Hong Kong Jockey Club Charities Trust. 


\section{REFERENCES}

[1] D. T. L. Shek, "Adolescent developmental issues in Hong Kong: relevance to positive youth development programs in Hong Kong," International Journal of Adolescent Medicine and Health, vol. 18, no. 3, pp. 341354, 2006.

[2] D. T. L. Shek, "School drug testing: a critical review of the literature," TheScientificWorldJournal, vol. 10, pp. 356-365, 2010.

[3] Tsuen Wan Centre and Chinese YMCA of Hong Kong, study on Adolescents' Internet Using Behaviors, Tsuen Wan Centre and Chinese YMCA of Hong Kong, Hong Kong, 2004.

[4] T. C. F. Chan, "Cyberrisk of Hong Kong youngsters," Journal of Youth Studies, vol. 7, no. 2, pp. 155-168, 2004.

[5] W. S. Yip and Y. K. Kwok, Adolescents' Computer Using Phenomena, Hong Kong Christian Service, Hong Kong, 2005.

[6] Against Child Abuse, "The Impacts of Internet on Junior Secondary School Students: A Research Report," Tech. Rep., Against Child Abuse, Hong Kong, 2004.

[7] C. W. Choi, K. T. Wu, K. K. Zah, and C. W. Ying, "The Impacts of Internet on Adolescents' Family Relationships and Mental Health: A Research Report,” Tech. Rep., Hong Kong Family Welfare Society, Hong Kong, 2005.

[8] D. T. L. Shek, V. M. Y. Tang, and C. Y. Lo, "Internet addiction in Chinese adolescents in Hong Kong: assessment, profiles, and psychosocial correlates," TheScientificWorldJournal, vol. 8, pp. 776-787, 2008.

[9] D. T. L. Shek, V. M. Y. Tang, and C. Y. Lo, "Evaluation of an Internet addiction treatment program for Chinese adolescents in Hong Kong," Adolescence, vol. 44, no. 174, pp. 359-373, 2009.

[10] Hong Kong Federation of Youth Groups, Youth Trends in Hong Kong 2003, Hong Kong Federation of Youth Groups, Hong Kong, 2005.

[11] E. Atwater, Adolescence, Prentice Hall, Englewood Cliffs, NJ, USA, 3rd edition, 1992.

[12] S. Alters and W. Schiff, Essential Concepts for Healthy Living, Jones and Bartlett Publishers, Sudbury, Mass, USA, 2nd edition, 2001.

[13] Wikipedia, "Adolescent sexuality in the United States," 2010, http://en.wikipedia.org/wiki/Adolescent_sexuality_ in_the_United_States.

[14] Kaiser Family Foundation, "U.S. Teen SexualActivity," 2005, http://www.kff.org/youthhivstds/upload/ U-STeen-Sexual-Activity-Fact-Sheet.pdf.

[15] D. J. Whitaker and K. S. Miller, "Parent-adolescent discussions about sex and condoms: impact on peer influences of sexual risk behavior," Journal of Adolescent Research, vol. 15, no. 2, pp. 251-273, 2000.

[16] W. A. Leigh and J. L. Andrews, "Peer influence on sexual behavior: what weknow about African American teens," Joint Center for Political and Economic Studies, Washington, DC, USA, 2002, http://www.aecf.org/upload/ publicationfiles/peer\%20influence\%20sexual\%20behavior.pdf.

[17] H. K. Ma, D. T. Shek, P. C. Cheung, and R. Y. Lee, "The relation of prosocial and antisocial behavior to personality and peer relationships of Hong Kong Chinese adolescents," Journal of Genetic Psychology, vol. 157, no. 3, pp. 255-266, 1996.

[18] H. D. Grotevant, "Adolescent development in family contexts," in Handbook of Child Psychology, W. Damon and N. Eisenberg, Eds., pp. 1097-1149, John Wiley \& Sons, New York, USA, 5th edition, 1998.

[19] T. M. McDevitt and J. E. Ormrod, Child Development and Education, Merrill Prentice Hall, Upper Saddle River, NJ, 3rd edition, 2007.

[20] D. S. W. Wong, "School bullying and tackling strategies in Hong Kong," International Journal of Offender Therapy and Comparative Criminology, vol. 48, no. 5, pp. 537-553, 2004.

[21] H. K. Ma, "How to prevent and reduce school bullying: a whole-person education proposal," in From Bullying to Caring, K. B. Yiu, C. Fong, W. L. Tsui Yip, and T. Y. Law, Eds., pp. 65-73, Educational Publisher, Hong Kong, 2005.

[22] G. Wurf, "Reducing bullying in high schools: an evaluation of school-based initiatives for the prevention and management of bullying," 2010, http://www.aare.edu.au/08pap/wur08639.pdf.

[23] K. H. Ma, "An analysis of the nature and causes of bullying and the proposal of Educare as its solution," in From Bullying to Caring, K. B. Yiu, C. Fong, W. L. Tsui Yip, and T. Y. Law, Eds., pp. 82-106, Educational Publisher, Hong Kong, 2005. 
[24] Commission on Youth, Study on Civic Awareness and Moral Values of Youth, Government of the Hong Kong Special Administrative Region, Hong Kong, 2000.

[25] D. Y. F. Ho, "Chinese patterns of socialization: a critical review," in The Psychology of the Chinese People, M. H. Bond, Ed., pp. 1-37, Oxford University Press, Hong Kong, 1986.

[26] R. E. Mitchell, Pupil, Parent, and School: a Hong Kong Study, Oriental Cultural Service, Taipei, Taiwan, 1972.

[27] Hong Kong Christian Service, "Press release on youth's opinion of the "compensated dating" survey," (in Chinese), 2009, http://www.hkcs.org.

[28] D. T. L. Shek, "Tackling adolescent substance abuse in Hong Kong: where we should and should not go," TheScientificWorldJournal, vol. 19, no. 7, pp. 2021-2030, 2007.

[29] S. E. U. Kerns and R. J. Prinz, "Critical issues in the prevention of violence-related behavior in youth," Clinical Child and Family Psychology Review, vol. 5, no. 2, pp. 133-160, 2002.

[30] R. C. Granger, "Creating conditions linked to positive youth development," in Pathways to Positive Development Among Diverse Youth, R. M. Lerner, C. S. Taylor, and A. von Eye, Eds., pp. 149-164, Jossey-Bass, San Francisco, Calif, USA, 2002.

[31] R. F. Catalano, M. L. Berglund, J. A. M. Ryan, H. S. Lonczak, and J. D. Hawkins, "Positive youth development in the united states: research findings on evaluations of positive youth development programs," Annals of the American Academy of Political and Social Science, vol. 591, pp. 98-124, 2004.

[32] S. T. Hauser, "Understanding resilient outcomes: adolescent lives across time and generations," Journal of Research on Adolescence, vol. 9, no. 1, pp. 1-24, 1999.

[33] C. Smith and B. E. Carlson, "Stress, coping, and resilience in children and youth," Social Service Review, vol. 71, no. 2, pp. 231-256, 1997.

[34] R. Jessor, M. S. Turbin, F. M. Costa, Q. Dong, H. Zhang, and C. Wang, "Adolescent problem behavior in China and the United States: a cross-national study of psychosocial protective factors," Journal of Research on Adolescence, vol. 13, no. 3, pp. 329-360, 2003.

[35] P. C. Scales and N. Leffert, Developmental Assets: A Synthesis of the Scientific Research on Adolescent Development, Search Institute, Minneapolis, Minn, USA, 1999.

[36] S. J. Wilson and M. Lipsey, "The effects of school-based social information processing interventions on aggressive behavior, part I: universal programs," Campbell Collaboration Systematic Review, vol. 5, 2006.

[37] R. E. Tremblay, L. Pagani-Kurtz, L. C. Masse, F. Vitaro, and R. O. Pihl, "A bimodal preventive intervention for disruptive kindergarten boys: its impact through mid-adolescence," Journal of Consulting and Clinical Psychology, vol. 63, no. 4, pp. 560-568, 1995.

[38] D. T. L. Shek, "Positive youth development and behavioral intention to gamble among Chinese adolescents in Hong Kong," International Journal of Adolescent Medicine and Health, vol. 22, no. 1, pp. 163-172, 2010.

[39] R. C. F. Sun and D. T. L. Shek, "Life satisfaction, positive youth development, and problem behaviour among Chinese adolescents in Hong Kong," Social Indicators Research, vol. 95, no. 3, pp. 455-474, 2010.

[40] R. C. F. Sun and D. T. L. Shek, "Positive youth development, life satisfaction and problem behavior among Chinese adolescents in Hong Kong: a replication," Social Indicators Research. In press.

[41] D. T. L. Shek and H. K. Ma, "Editorial: evaluation of the project P.A.T.H.S. in Hong Kong: are the findings replicable across different populations?" TheScientificWorldJournal, vol. 10, pp. 178-181, 2010.

[42] D. T. L. Shek and R. C. F. Sun, "Effectiveness of the tier 1 program of project P.A.T.H.S.: findings based on three years of program implementation," TheScientificWorldJournal, vol. 10, pp. 1509-1519, 2010.

[43] D. T. L. Shek and C. M. S. Ma, "Impact of the project P.A.T.H.S. in the junior secondary school years: individual growth curve analyses," TheScientific WorldJournal, vol. 11, pp. 253-266, 2011.

[44] D. T. L. Shek and L. Yu, "Prevention of adolescent problem behavior: longitudinal impact of the project P.A.T.H.S. in Hong Kong,” TheScientificWorldJournal, vol. 11, pp. 546-567, 2011.

\section{This article should be cited as follows:}

Daniel T. L. Shek, Hing Keung Ma, and Rachel C. F. Sun, "A Brief Overview of Adolescent Developmental Problems in Hong Kong,” TheScientificWorldJOURNAL, vol. 11, pp. 2243-2256, 2011. 